\title{
Correlation between anthropometric measurements and hypertension in Oman
}

\author{
Sanam Anwar 1,", Hajir Hamed Rashid ${ }^{2}$, Bushra Aleem ${ }^{3}$, Ghadeer Jamal Moslhey ${ }^{4}$, Asma Said Al Rashdi ${ }^{5}$ \\ ${ }^{1} \mathrm{HOD},{ }^{2-5}$ Resident, Dept. of Epidemiology \& Public Health, College of Medicine \& Health Sciences, National University of Science and \\ Technology, Oman
}

\section{*Corresponding Author: Sanam Anwar}

Email: sanam@omc.edu.om

\begin{abstract}
Introduction: Evidence that hypertension is related to increase in body fat is well established in literature. Evidence gathered from several studies shows that central obesity is a greater risk factor for cardiovascular diseases. Oman has witnessed an epidemiological transition to non-communicable diseases.

Objectives: The objective of the study was to examine the correlation between different anthropometric indicators and hypertension in Omani adults.

Materials and Methods: A total of 500 adults participated in this study after taking informed consent from them. All participants underwent blood pressure and anthropometric measurements using standard procedures. The population study was separated in males and females and the effect of anthropometric measurements was compared for normotensive and hypertensive population. Correlation of anthropometric measurements with mean systolic and diastolic blood pressure was observed.

Results: Mean values of all anthropometric measurements were significantly higher in hypertensive compared to people with normal blood pressure across both the gender. In both males and females; hip circumference, waist circumference, waist height ratio and BMI had significant strong positive correlation with mean systolic blood pressure $(\mathrm{p}<0.01)$. Females had significant strong positive correlation of all anthropometric measurements with diastolic blood pressure $(\mathrm{p}<0.01)$; hip circumference $(\mathrm{r}=0.310)$, waist circumference $(\mathrm{r}=0.283)$, body mass index $(r=0.273)$, waist height ratio $(r=0.260)$. However, in males only waist circumference and hip circumference had significant but weak positive correlation with diastolic blood pressure $(\mathrm{p}<0.05)$. The AUC for predicting hypertension for all anthropometric indicators was significantly more than $0.7(\mathrm{p}<0.01)$.

Conclusion: Simple anthropometric measurements like hip circumference, waist circumference and waist height ratio can be used to predict hypertension in both males and females.
\end{abstract}

Keywords: Hip circumference, AUC, Correlation, Body mass index, Hypertension.

\section{Introduction}

The prevalence of obesity has reached epidemic proportions in both industrialized and developing countries; urban and rural communities alike. Evidence that hypertension is related to increases in body fat is well established in literature. ${ }^{1,2}$ However, there are controversial opinions on their relationship with the distribution of body fat. To discriminate the amount of body fat and its distribution, anthropometric indicators have proven to be effective, especially in epidemiological studies with larger samples. Evidence gathered from several studies shows that central obesity is a greater risk factor for cardiovascular diseases compared to other types of obesity. ${ }^{3}$ While the body mass index predicts the overall fat, waist circumference identifies the fat located in the central region of the body; waist height ratio considers the proportion of central fat by the individual's height. This has led investigators to use various anthropometric measurements such as waist circumference, waist height ratio, hip circumference, total body fat and skin fold thickness to establish which of these variables would show better association with cardiovascular diseases or help predict risk. ${ }^{4,5}$ Several epidemiological studies from different populations have reported significant association between different anthropometric indicators and blood pressure levels. ${ }^{6-10}$ Among the anthropometric indicators, BMI and waist circumference have been widely used in the detection of cardiovascular risk factors. ${ }^{11}$ Currently, some studies especially in Asian populations, have used waist height ratio to predict central fat and associated risk factors. ${ }^{12}$

Oman has witnessed an epidemiological transition to non-communicable diseases possibly due to number of factors including changes in lifestyle together with demographic changes as evident by aging of the population. Non-communicable diseases contributed $42.5 \%$ of the outpatient morbidity in 1996 compared to $47.6 \%$ in 2015 . Cardiovascular diseases are the leading cause of deaths; hypertension, hypercholesterolemia, obesity and diabetes are on the rise. The prevalence of hypertension has increased from $32 \%$ in 2000 to $40 \%$ in $2008 .{ }^{13}$ Overweight and obesity in Oman are present in $30 \%$ and $20 \%$ adults respectively and is known risk factor for cardiovascular risk. The present study was therefore undertaken with the objective to examine the correlation between different anthropometric indicators and hypertension in Omani adults.

\section{Materials and Methods}

A total of 500 adults participated in this study after taking informed consent from them. The participants were visitors attending the polyclinic in South Batinah governorate; research was approved by the Ministry of Health, Oman. All participants underwent blood pressure and anthropometric measurements. After about $10 \mathrm{~min}$ of quiet sitting, three readings of blood pressure were taken at intervals of 3 to 5 minutes using mercury sphygmomanometer. The mean blood pressure value was 
used for analysis. Based on the WHO and International Society of Hypertension guidelines; a cutoff point of 140/90 mmHg for hypertension was used..$^{14}$ Participants with blood pressure value less than or equal to $140 / 90 \mathrm{mmHg}$ were considered normotensive while those with higher values or who reported to be on new antihypertensive medications were classified as hypertensive. Weight and height were measured with Detecto scale. The body mass index (BMI) was calculated as Weight/Height $\left.{ }^{2}\left(\mathrm{~kg} / \mathrm{m}^{2}\right)\right)$. A non-elastic measuring tape was used to determine waist circumference at the smallest diameter of the waist and hip circumference at the widest diameter of the buttocks. ${ }^{15}$ Participants were advised to stand erect with both feet together, arms at the side and not retract abdomen during measurement. All measurements were recorded to the nearest centimeter. Waist height ratio was calculated by dividing waist circumference in centimeter by height in centimeter.

Data was entered and analyzed in SPSS version 22. Mean and standard error was calculated for anthropometric measurements in normotensive and hypertensive population after separating the population into males and females. For comparing means in two groups, independent student's $t$ test was used as the test of significance. Partial correlation coefficients after adjusting for age were calculated to see correlation between anthropometric measurements and mean systolic and diastolic blood pressure values. ROC curve analysis was done to find out the Area under the curve (AUC); in order to see how well the test separates the group being tested into those with and without hypertension. A p value of less than 0.05 was interpreted as a statistically significant test.

\section{Results}

Out of 500 participants who were recruited in the study, 147 were females and 353 were males. Mean age of participants was 44 years; females had a significantly higher mean age than males $(p<0.01)$. Mean weight of participants was $71.8 \mathrm{~kg}$; males had a significantly higher mean weight than females $(\mathrm{p}<0.01)$. Females on the other hand had significantly higher mean waist height ratio than males $(\mathrm{p}<0.05)$. Mean systolic blood pressure was $130.9 \mathrm{mmHg}$ and was same for both the genders. Mean diastolic blood pressure was $85.5 \mathrm{mmHg}$, mean BMI was 27.1 , mean waist circumference was $90.9 \mathrm{~cm}$, and mean hip circumference was $105.2 \mathrm{~cm}$; however these parameters were not statistically different across both the genders (Table 1).
The differences in anthropometric measurements between normotensive and hypertensive population were explored in Table 2. Mean values of waist circumference and hip circumference were significantly higher in hypertensive compared to people with normal blood pressure across both the gender $(\mathrm{p}<0.01)$. Waist height ratio and body mass index was also significantly higher in male hypertensive population $(\mathrm{p}<0.01)$ but the difference was not significant for females.

Relationship of anthropometric measurements (BMI, waist circumference, hip circumference, waist height ratio) with both mean systolic blood pressure and mean diastolic blood pressure was explored by partial correlation coefficients controlled for age (Table 3 ). In both males and females, all the anthropometric measurements had significant strong positive correlation with mean systolic blood pressure $(\mathrm{p}<0.01)$. Hip circumference had the strongest correlation, $(r=0.363$ in males, $r=0.341$ in females). With mean systolic blood pressure, the next strongest correlation was with body mass index in females while in males it was with waist circumference. Females had significant strong positive correlation of all anthropometric measurements with diastolic blood pressure $(\mathrm{p}<0.01)$. Hip circumference $(\mathrm{r}=0.310)$ had the strongest correlation followed by waist circumference $(r=0.283)$ and then body mass index $(r=0.273)$. However, in males only waist circumference and hip circumference had significant but weak positive correlation with diastolic blood pressure $(\mathrm{p}<0.05)$; while waist height ratio $(\mathrm{r}=0.105)$ and BMI $(\mathrm{r}=$ $0.093)$ did not have a significant correlation $(p>0.05)$ with diastolic blood pressure.

Receiver operating characteristic curves (ROC) analysis of anthropometric measurements with hypertension is shown in Table 4. Area under the curve (AUC) was used to indicate the degree of accuracy in prediction of hypertension from anthropometric measurements. AUC more than 0.5 indicates positive predictive power of studied variables. All the anthropometric measurements showed significant predictive ability to discriminate hypertensive from normotensive population $(\mathrm{p}<0.001)$. Hip circumference had the best predictive ability (AUC $=0.724$ in females, $\mathrm{AUC}=$ 0.708 in males) followed by waist height ratio and then waist circumference in both males and females (Fig. $1 \& 2$ ). BMI had the least AUC. AUC was significantly higher in females than males for all anthropometric measurements.

Table 1: Descriptive characteristics of study population

\begin{tabular}{|l|c|c|}
\hline Variable & Females $($ Mean \pm S.E) & Males $($ Mean \pm S.E) \\
\hline Age $($ years $)$ & $48.52 \pm 1.53$ & $42.36 \pm 0.97$ \\
\hline Mean SBP $(\mathrm{mmHg})$ & $130.89 \pm 1.21$ & $130.92 \pm 0.70$ \\
\hline Mean DBP $(\mathrm{mmHg})$ & $84.09 \pm 0.82$ & $86.12 \pm 0.98$ \\
\hline Waist circumference $(\mathrm{cm})$ & $90.84 \pm 1.81$ & $91.03 \pm 0.92$ \\
\hline Hip circumference $(\mathrm{cm})$ & $106.44 \pm 1.94$ & $104.70 \pm 1.04$ \\
\hline Waist height ratio & $0.58 \pm 0.01$ & $0.55 \pm 0.01$ \\
\hline Weight $(\mathrm{kg})$ & $67.25 \pm 1.24$ & $73.68 \pm 0.75$ \\
\hline Body mass index $\left(\mathrm{kg} / \mathrm{m}^{2}\right)$ & $27.05 \pm 0.47$ & $27.12 \pm 0.29$ \\
\hline
\end{tabular}


Table 2: Anthropometric indicators of hypertensive vs normotensive study population

\begin{tabular}{|l|c|c|c|c|c|c|}
\hline Variable & \multicolumn{3}{|c|}{ Females } & \multicolumn{3}{c|}{ Males } \\
\cline { 2 - 7 } & $\begin{array}{c}\text { Normotensive } \\
\text { (Mean } \pm \text { S.E) }\end{array}$ & $\begin{array}{c}\text { Hypertensive } \\
\text { (Mean } \pm \text { S.E) }\end{array}$ & $\begin{array}{c}\text { p } \\
\text { value }\end{array}$ & $\begin{array}{c}\text { Normotensive } \\
\text { (Mean } \pm \text { S.E) }\end{array}$ & $\begin{array}{c}\text { Hypertensive } \\
\text { (Mean } \pm \text { S.E) }\end{array}$ & $\begin{array}{c}\text { p } \\
\text { value }\end{array}$ \\
\hline Waist circumference & $85.05 \pm 1.74$ & $101.12 \pm 3.57$ & 0.010 & $86.51 \pm 0.99$ & $97.13 \pm 1.57$ & 0.000 \\
\hline Hip circumference & $99.38 \pm 1.78$ & $118.95 \pm 3.82$ & 0.004 & $98.76 \pm 1.09$ & $112.73 \pm 1.77$ & 0.000 \\
\hline Waist height ratio & $0.54 \pm 0.01$ & $0.64 \pm 0.02$ & 0.218 & $0.52 \pm 0.01$ & $0.59 \pm 0.01$ & 0.000 \\
\hline Body mass index & $25.74 \pm 0.59$ & $29.34 \pm 0.66$ & 0.829 & $26.00 \pm 0.31$ & $28.62 \pm 0.51$ & 0.002 \\
\hline
\end{tabular}

(Waist circumference and Hip circumference are expressed in $\mathrm{cm} ; \mathrm{BMI}$ in $\mathrm{kg} / \mathrm{m}^{2}$ )

Table 3: Partial correlation coefficients between anthropometric indicators and blood pressure controlled for age

\begin{tabular}{|c|c|c|c|c|c|c|c|c|}
\hline \multirow[t]{3}{*}{ Variable } & \multicolumn{4}{|c|}{ SBP } & \multicolumn{4}{|c|}{ DBP } \\
\hline & \multicolumn{2}{|c|}{ Females } & \multicolumn{2}{|c|}{ Males } & \multicolumn{2}{|c|}{ Females } & \multicolumn{2}{|c|}{ Males } \\
\hline & $\mathbf{r}$ & p value & $\mathbf{r}$ & p value & $\mathbf{r}$ & p value & $\mathbf{r}$ & p value \\
\hline Waist circumference & 0.275 & 0.001 & 0.299 & 0.000 & 0.283 & 0.001 & 0.123 & 0.022 \\
\hline Hip circumference & 0.363 & 0.000 & 0.341 & 0.000 & 0.310 & 0.000 & 0.137 & 0.010 \\
\hline Waist height ratio & 0.279 & 0.001 & 0.276 & 0.000 & 0.260 & 0.002 & 0.105 & .050 \\
\hline Body mass index & 0.282 & 0.001 & 0.231 & 0.000 & 0.273 & 0.001 & 0.093 & 0.082 \\
\hline
\end{tabular}

Table 4: ROC curve analysis of anthropometric indicators and hypertension

\begin{tabular}{|l|c|c|c|c|c|c|}
\hline \multirow{2}{*}{ Variable } & \multicolumn{3}{|c|}{ Females } & \multicolumn{3}{c|}{ Males } \\
\cline { 2 - 7 } & AUC & $\mathbf{9 5 \%}$ CI & p value & AUC & 95\% CI & p value \\
\hline Waist circumference & 0.705 & $0.614-0.796$ & 0.000 & 0.683 & $0.625-0.741$ & 0.000 \\
\hline Hip circumference & 0.724 & $0.638-0.811$ & 0.000 & 0.708 & $0.652-0.764$ & 0.000 \\
\hline Waist height ratio & 0.707 & $0.619-0.794$ & 0.000 & 0.685 & $0.625-0.744$ & 0.000 \\
\hline Body mass index & 0.703 & $0.615-0.791$ & 0.000 & 0.665 & $0.607-0.724$ & 0.000 \\
\hline
\end{tabular}

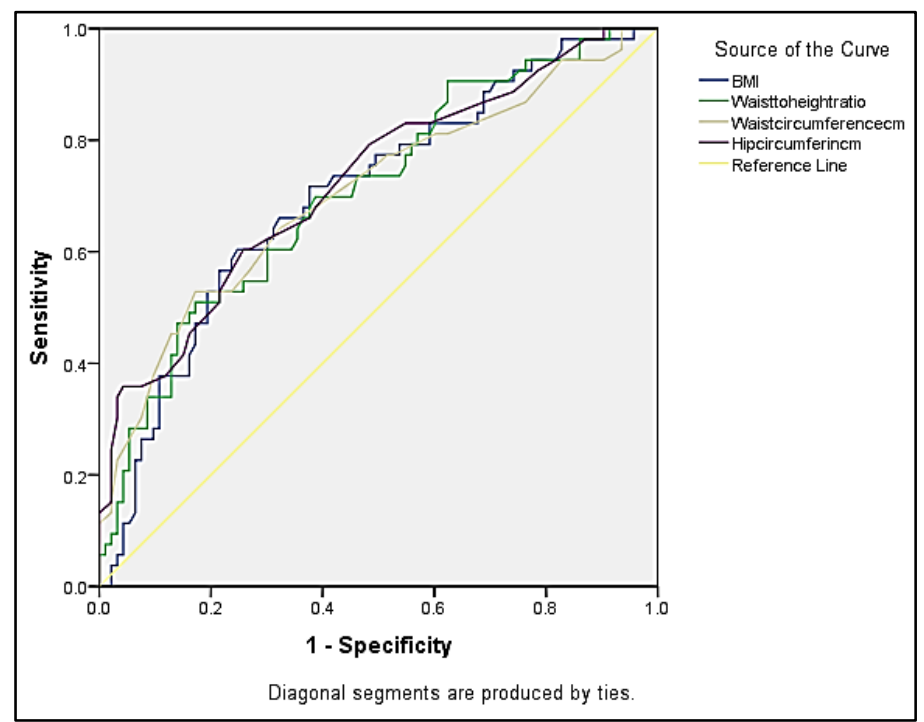

Fig. 1: ROC Curve for females 


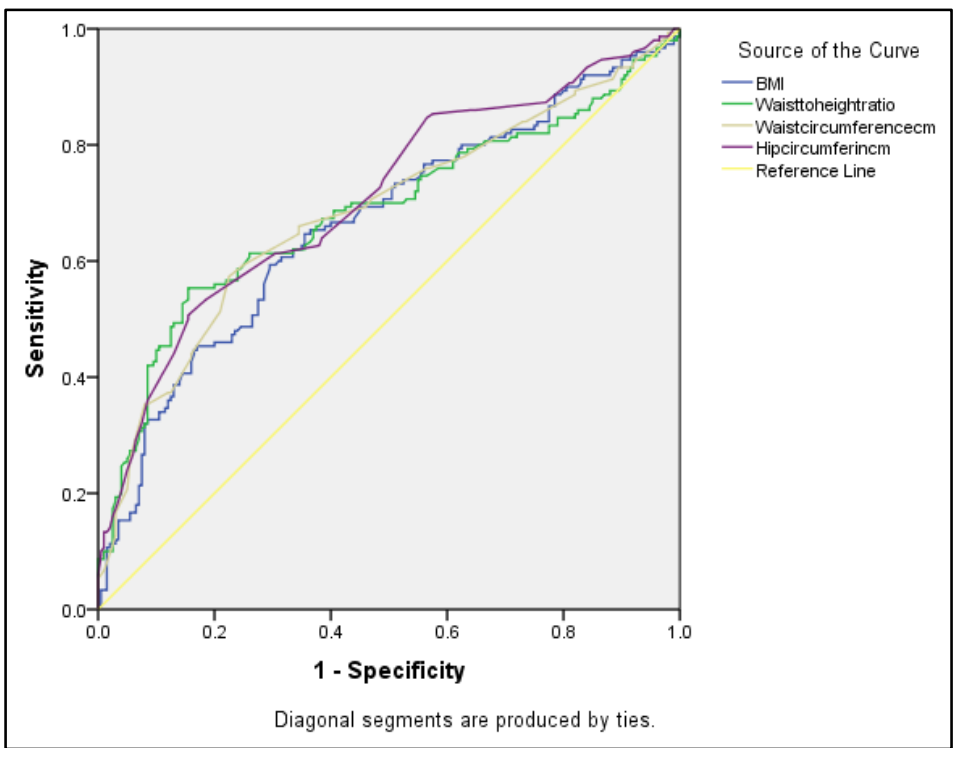

Fig. 2: ROC curve for males

\section{Discussion}

It is of utmost importance to determine valid anthropometric measurements that may be useful for predicting obesity related cardiovascular disease risk in adults. The present study showed that all the studied anthropometric indicators had good predictive ability for higher blood pressure $(p<0.001)$ as seen from the area under the ROC curve. However the best predictor was hip circumference followed by waist circumference and then hip circumference in both males and females; BMI had the least AUC. Similar findings were seen in the study by Maken et al who observed that BMI did not show a very good area under the ROC curve; waist height ratio was the best predictor, followed by waist circumference among males; among females, waist height ratio was the best predictor, followed by waist circumference and body mass index. ${ }^{16}$ In another study, in males only waist circumference (AUC $=0.676)$ and waist height ratio $(\mathrm{AUC}=0.658)$ showed significant ability to discriminate higher blood pressure while in females all four anthropometric indicators (AUC>0.7) were significant. ${ }^{17}$ In another study conducted in Oman, the BMI (AUC $=0.766)$ and waist circumference $(\mathrm{AUC}=0.772)$ predicted prevalent CVD risk factors equally well. ${ }^{18}$

The mean waist circumference of the population was $90.9 \mathrm{~cm}$, hip circumference was $105.2 \mathrm{~cm}$ and body mass index was $27.1 \mathrm{~cm}$ in the present study which is in accordance with the findings by Riyami et al in Oman survey which showed high mean values of waist circumference and hip circumference. ${ }^{19}$ In the present study mean values of all anthropometric measurements were significantly higher in hypertensive males; however in females only waist circumference and hip circumference had statistically significantly higher mean values. Different studies reported increased BMI and waist circumference increased the risk of high systolic and diastolic blood pressure. ${ }^{20,21}$ Doll et al found a linear relation between systolic and diastolic blood pressure with BMI, waist hip circumference ratio and waist circumference. ${ }^{22}$

The present study found a significant correlation between all anthropometric indicators and mean systolic and diastolic blood pressure in females and males; except that in males only hip and waist circumference were significantly associated with diastolic blood pressure. Maximum correlation was seen with hip circumference and waist circumference. BMI correlated less with both mean systolic and diastolic blood pressure across both gender even though the mean BMI of hypertensive was higher than normotensive. Janssen et al reported waist circumference and not BMI explains obesity related health risk including hypertension. ${ }^{23}$ In contrast to these findings Gus et al reported that body mass index is associated with hypertension in both the genders. ${ }^{24}$

In a South African study, there was significant correlation in females between mean systolic blood pressure and waist circumference $(\mathrm{r}=0.360)$, hip circumference $(\mathrm{r}=0.292)$; mean diastolic blood pressure and waist circumference $(\mathrm{r}=0.216)$; while in males only weak and nonsignificant correlations were noted. Similar to the present study their hypertension status correlated less well with BMI. ${ }^{17}$ Choy et al, showed an association between increased waist circumference and raised blood pressure. ${ }^{25}$ Dalton et al reported that BMI, waist circumference and waist-hip ratio were equally related with hypertension. ${ }^{26}$ Several studies have shown that a larger hip circumference is protective against hypertension and metabolic diseases. ${ }^{16}$ Studies have demonstrated that without controlling for BMI or waist circumference, hip circumference was associated with higher blood pressure in females. ${ }^{17}$

\section{Conclusion}

Mean values of waist circumference, hip circumference, waist height ratio and BMI were significantly higher in hypertensive compared to people with normal blood pressure across both the gender. There was positive 
correlation between all anthropometric indicators and systolic as well as diastolic blood pressure. However the best predictor was hip circumference followed by waist circumference and then hip circumference in both males and females. Higher values of hip and waist circumference being modestly associated with hypertension, highlights the importance of using these simple anthropometric measurements to predict hypertension in both males and females. It also emphasizes the importance of weight reduction as an effective method of preventing and controlling hypertension in Omani adults.

\section{Acknowledgements}

The authors duly acknowledge the financial support given by the Research Council as FURAP grant. The authors also acknowledge the cooperation of the Rustaq polyclinic staff.

\section{Conflict of Interest: Nil.}

\section{References}

1. Bao W, Threefoot SA, Srinivasan SR, Berenson GS. Essential hypertension predicted by tracking of elevated blood pressure from childhood to adulthood: the Bogalusa Heart Study. Am J Hypertens. 1995;8(7):657-665.

2. Reddy KSN, Reddy KK, Sudha G. Overall and abdominal adiposity on blood pressure: consistency and evaluation of their association in an adult Indian population. J Life Sci. 2010;2:117-125.

3. Lee CM, Huxley RR, Widman RP, Woodward M. Indices of abdominal obesity are better discriminators of cardiovascular risk factors than BMI: a meta-analysis. J Clin Epid. 2008;61:646-653.

4. Van Dijk SB, Takken T, Prinsen EC, Wittink H. Different anthropometric adiposity measures and their association with cardiovascular disease risk factors: a meta-analysis. Neth Heart J. 2012;20:205-218.

5. Chen L, Peters A, Magliano DJ, Welbom TA, Wolfe R, Zimmet PZ, Tonkin AM. Anthropometric measures and absolute cardiovascular risk estimates in the Australian Diabetes, Obesity and Lifestyle (AUSBIAB) Study. Eur J Cardiovasc Prev Rehabil. 2007;14:740-745.

6. Gupta R, Mehrishi S. Waist-hip ratio and blood pressure correlation in an urban Indian population. J Indian Med Assoc. 1997;95:412-415

7. Kaufman JS. Asuzu MC, Mufunda J. Relationship between blood pressure and body mass index in lean populations. Hypertension. 1997;30:1511-1516.

8. Olatunbosun ST, Kaufman JS, Cooper RS. Hypertension in a black population: prevalence and biosocial determinants of high blood pressure in a group of urban Nigerians. J Hum Hypertens. 2000;14:249-257.

9. Shanthirani CS, Pradeepa R, Deepa R. Prevalence and risk factors of hypertension in selected South Indian population the Chennai Urban Population Study. J Assoc Physicians India. 2003; 51:20-7.

10. Stamler J. Epidemiologic findings on body mass and blood pressure in adults. Ann Epidemiol. 1991;1:347-362.

11. Ng VWS, Kong APS, Choi KC, Ozaki R, Wong GWK, So WY, et al. BMI and waist circumference in predicting cardiovascular risk factor clustering in Chinese adolescents. Obesity. 2007;15:494-503.

12. Sung RY, So HK, Choi KC, Nelson EAS, Li AM and Yin JAT, et al. Waist circumference and waist-to-height ratio of
Hong Kong Chinese children. BMC Public Health 2008;8:324.

13. Rashid Al- Saadi, Sulaiman Al-Shukaili, Suleiman AlMahrazi, Zakiya Al-Busaidi: Prevalence of Uncontrolled Hypertension in Primary Care Settings in Al Seeb Wilayat, Oman. SQU Med J. 2011;11(3):349-356.

14. World Health Organization-International Society of Hypertension Guidelines for the Management of Hypertension. Guidelines Subcommittee. Hypertens. 1999;17:151-183.

15. WHO STEP wise approach to surveillance (STEPS). 2008; Geneva, World Health Organization (WHO)

16. Anthropometric indicators as predictors of high blood pressure among the AO tribe of North-East India. Temsutola Maken and Lalhmunlien Robert Varte. Asian J Med Sci. 2013;4:15-22.

17. Nkeh-Chungag BN, Mxhosa TH, Mgoduka PN. Association of waist and hip circumferences with the presence of hypertension and pre-hypertension in young South African adults. Afri Health Sci. 2015;15(3):908-916.

18. Al Lawati J.A, Jousilahti P. Body mass index, waist circumference and waist-to-hip ratio cut-off points for categorisation of obesity among Omani Arabs. Public Health Nutr. 2008;11(1):102-108.

19. Asya Al Riyami, Mahmoud Attia Abd Elaty, Magdi Morsi, Hilal Al Kharusi, Waleed Al Shukaily, Sanjay Jaju. Oman World Health Survey: Part 1 - Methodology, Sociodemographic Profile and Epidemiology of NonCommunicable Diseases in Oman. Oman Med J. 2012;27(5):425-443.

20. Wilsgaard T, Schirmer H, Arnesen E. Impact of body weight on blood pressure with a focus on sex differences: the Tromso Study, 1986-1995. Arch Intern Med. 2000;160(18):2847-2853.

21. Gryglewska B, Grodzicki T, Kocemba J. Obesity and blood pressure in the elderly free-living population. J Hum Hypertens. 1998;12(9):645-647.

22. Doll S, Paccaud F, Bovet P, Burnier M, Wietlisbach V. Body mass index, abdominal adiposity and blood pressure: consistency of their association across developing and developed countries. Int J Obes Relat Metab Disord. 2002;26(1):48-57.

23. Janssen I, Katzmarzyk PT, Ross R. Body mass index, waist circumference, and health risk: evidence in support of current National Institutes of Health guidelines. Arch Intern Med. 2002;162(18):2074-2079.

24. Gus M, Fuchs SC, Moreira LB, Moraes RS, Wiehe M, Silva AF, Albers F, Fuchs FD. Association between different measurements of obesity and the incidence of hypertension. Am J Hypertens. 2004;17:50-53.

25. Choy CS, Chan WY, Shih CC, Wu LC, Liao CC. Waist circumference and risk of elevated blood pressure in children: a cross sectional study. BMC Public Health. 2011;11:613 -619.

26. Dalton M, Cameron AJ, Zimmet PZ, Shaw JE, Jolley D, Dunstan DW, Welborne TA. Waist circumference, waist-hip ratio and body mass index and their correlation with cardiovascular disease risk factors in Australian adults. J Intern Med. 2003;254(6):555-563.

27. Severinsen MT, Kristensen SR, Johnsen SP, Dethlefsen C, Tjonneland A, Overvad K. Anthropometry, body fat and venous thromboembolism. Circulation. 2009;120:1850-1857.

28. Parker ED, Pereira MA, Stevens J, Folsom AR. The atherosclerosis risk in community study. Epidemiol. 2009;169:837-847.

How to cite this article: Anwar S, Rashid $\mathrm{H}$. $\mathrm{H}$, Aleem B, Moslhey G J, Al Rashdi A. S. Correlation between anthropometric measurements and hypertension in Oman. J Prev Med Holistic Health. 2018;4(2):83-87. 